the impression, which for my part I have long entertained, that their beneficial effects are due to some other mode of action which it would be important to investigate and opens up the question as to the nature and the range of their usefulness. Internal therapeutics bave not yet been reduced to the exclusive administration of antiseptics only, and if other remedies are still worth administering by the mouth for the treatment of intravascular conditions such as atheroma, aneurysm, endocarditis, and blood diseases in general, it may not be unreasonable to keep an open mind as to the possible advantages of the shorter route. This also applies to the treatment of pulmonary affections, because of the directness of the road of access. In the case of acute pneumonia the effects I have obtained with injections of protargol have appeared to me to be sufficiently striking to deserve further consideration from the pathological, as well as from the clinical, standpoint. I am not prepared to say whether the rapid reduction in temperature and the manifest general improvement in the clinical condition of the patients were due to the minute dose of protargol (from one half to one grain) or to the bulk (from 20 to 40 cubic centimetres) of the saline solution injected. Possibly the normal saline solution alone might have acted as well. At any rate the successful employment of collargol in two cases of pneumonia has quite recently been reported by M. R. Moutard-Martin and M. P. Thaon, ${ }^{1}$ and at the same meeting $M$. Netter ${ }^{2}$ referred to his successful treatment of a very bad case of infective endocarditis by the same agent. The discovery of better remedies than the salts of silver may be hoped for in the future, but the results bitherto obtained with the help of the latter indicate that our study of the intravenous method should not be considered as closed but as barely opened as yet. I would be the last to advocate the indiscriminate use of this form of treatment. I have myself often refrained from using it because I consider that it should not be undertaken except by skilful and highly. trained operators. The procedure is difficult and not free from anxiety. These are also the limitations inherent to most of our life-saving surgical operations, but they have not been urged as arguments for depriving us of the benefit attaching to the risk.

I am, Sirs, yours faithfully,

Curzon-street, Mayfair, Jan. 12th, 1903. WM. EWART.

\section{THE THORNTON HEATH SLATE CLUB AND DR. W. B. ADDISON.}

To the Editors of THE LANCET.

SIRS,--By the kindness of a fellow practitioner my attention has been drawn to a paragraph in $1 \mathrm{HE}$ LANCET of Jan. 10th, p. 143, coupling my name with the word "advertisement." I enclose a letter from the secretary of the North Croydon Benefit Society showing that I was completely ignorant of the existence of the handbills you mention. I knew nothing of them ; the possibility of the existence of such things had never even entered my mind. I have now severed my connexion with the club, which contains only 53 members, and is the only club appointment I have held during the seven years I have been in practice here. By putting the word "Advertisement" over your paragraph you distiuctly accuse me of advertising. As I knew nothing of the handbills it is obvious that I have not been advertising and it is equally obvious that it is a scandalous thing that I should be accused by a paper of the supposed high standing of THE LANCET of doing a dicgraceful act without a shred of proof that I knew anything of the matter at all. Your advice to me to withdraw my connexion with such clubs is quite unnecessary ; my standard of medical etiquette is not only as high as any advocated by THE LANCET, but in view of the paragraph mentioned is really higher. Fortunately, my reputation among those of my fellow practitioners in this neighbourhood who are most anxious to uphold the dignity of the medical profession is such that I can honestly say they are more annoyed by your paragraph than $\mathbf{I}$ am.

If you have any wish at all that I should not be prejudged you will publish this letter in its entirety.

$$
\text { I am, Sirs, yours faithfully, }
$$
W. B. ADDison.

Parchmore-road, Thornton Heath, Jan. 12th, 1903.

$$
\text { [INCLOSURE.] }
$$

"Fernlea," Westbrook-roar, Thornton Heath, Jan. 11th, 1903 .

SrR,-It having come to my knowledge that a paragraph appeared in

1 Bulletin et Mémnire de la Société Médicale des Hôpitaux de Paris, Dec. 26th, 1902, p. 1151. 2 Ibid. your paper condemning Dr. Addison for allowing his name to be issued
on handbills distributed in this neighbourhood I wish most emphatically to state that it was done without any consent being obtained from Dr. Addison; the bills were all distributed before he knew anything abou it. I sincerely hope, in justice to Dr. Addison, and in order to allay anything I may have done to injure his reputation, you will publish this letter. I remain, yours truly. F. J. RUNDLE,

* We are glad to learn that Dr. W. B. Addison's name has been taken in vain by the club from which he has severed his connexion.-ED. L.

\section{THE MEDICAL MAN, THE CORONER, AND THE PATHOLOGIST.}

\section{To the Editors of THE LANCET.}

SIRS,-On Jan. 2nd I was called at 9.30 A.M. to see an infant at 76, Speke-road. On arriving at the house I found that the child had been dead some time, the hands were clenched, the thumbs were turned in, the toes were drawn up, the tongue protruded slightly through the gums, and there was some mucus on the nostrils; the sides of the face were a deep purple. The child had beer sleeping in bed with the parents who were in very poor circumstances. I sent the usual communication to the coroner's officer and the only acknowledgement $I$ received from the coroner was a verbal message that Dr. Freyberger would let me know when he was going to make the post-mortem examination.

I inclose a report of the case and you will observe that Mr. Truutbeck delivered a little homily to the jury in which he pointed out the importance of employing a pathologist of special skill in these cases. Now I have been making postmortem examinations in this neighbourbood for 18 years and 1 have given evidence before all the coroners who have held inquests in south-west London during that time. I have reported scores of similar cases in which the question always arises as to whether the convulsion, if any, which might have caused death arose from partial asphyxia due to overlaying or otherwise, and it stands to reason that the medical man who sees the child lying in the bed and who knows the people and their surroundings is in a far better position to judge of the case than a stranger who does not make a post-mortem examination until three clear days afterwards. I may mention here that the child was washed and laid out after $\mathbf{I}$ saw it, thus removing most of the external diagnostic signs, and there was nothing revealed by the post-mortem examination which could not be seen by any medical man who knew his work. In the circumstances I am utterly at a loss to understand the coroner's remarks, for there was nothing in the case calling for a special pathologist, while there was every reason to call in the medical man who first saw it.

I am, Sirs, yours faithfully,

LeONARD S. MCMANUS, M.D., M.Ch. R.U.I. St. John's Hill, S.W., Jan. 12th, 1902

** We cannot attempt to explain what cases Mr. Troutbeck considers "special." of course, the only medical witness who could help the jury in any practical way in such a case as the one detailed above was the practitioner who first saw the body.-ED. L.

Medical FolkLore-Recently at Luffincott, a little village in Cornwali, an unusual event took place. An agricultural labourer sat in the church porch on Sunday and collected half-a-crown in pennies from the congregation, the thirtieth donor giving a half-crown and taking up the 29 pence as change. A ring is to be made from the silver coin and by this ring the collector expects to be cured of fits. This is one of the relics of witcheraft which is still to be found in the remote parts of Devon and Cornwall.

The Therapeutical Society.-The object of this new society, as stated in the "rules" which have just peen issued, is "the advancement of knowledge in pharmacology and therapeutics by the holding of meetings, the reading of papers, the exhibition of drugs and specimens, and such other means as the council may determine." All duly qualified medical practitioners of either sex are eligible for fellowship, and the subscription is $10 s .6 d$. a year. Ordinary meetings will be held on one Tuesday afternoon in each winter month, from January, 1903, at 4 P.M. 